\title{
A POWER CONTROL SCHEME FOR DOUBLY-FED INDUCTION GENERATOR
}

\author{
Alfeu J. Sguarezi Filho and M. E. Oliveira Filho and Ernesto Ruppert \\ University of Campinas \\ FEEC-DSCE-UNICAMP CEP 13083 - 852 , Caixa Postal 6101, Campinas - SP, Brasil \\ sguarezi@dsce.fee.unicamp.br, mfilho@dsce.fee.unicamp.br, ruppert@fee.unicamp.br
}

\begin{abstract}
This paper proposes a power control scheme for doubly-fed induction generator for variable speed wind power generation. This scheme uses stator flux decoupling and deadbeat control loops. The algorithm of the deadbeat calculates the voltage vector to be supplied to the rotor in order to guarantee that the active and reactive power reach their desired reference values. Because the generator leakage inductance and resistance information were required for this control method, the influence of the estimation errors for these parameters was also investigated. Simulations results are carried out for validation of the digital controller operation.
\end{abstract}

Keywords - Doubly-fed induction generator, power control, wind energy,variable speed constant frequency applications.

\section{INTRODUCTION}

The renewable energy systems and specially wind energy have attracted interest due to the increasing concern about $\mathrm{CO}_{2}$ emissions. The wind energy systems using a doublyfed induction generator (DFIG) have some advantages due to variable speed operation and four quadrant active and reactive power capabilities compared with fixed speed induction squirrel cage and synchronous generators [1,2].

The stator of DFIG is connected directly to the grid and the rotor links the grid by a bi-directional converter as shown in Figure 1. The rotor converter objective aims to the DFIG active and reactive power control between the stator and ac supply.

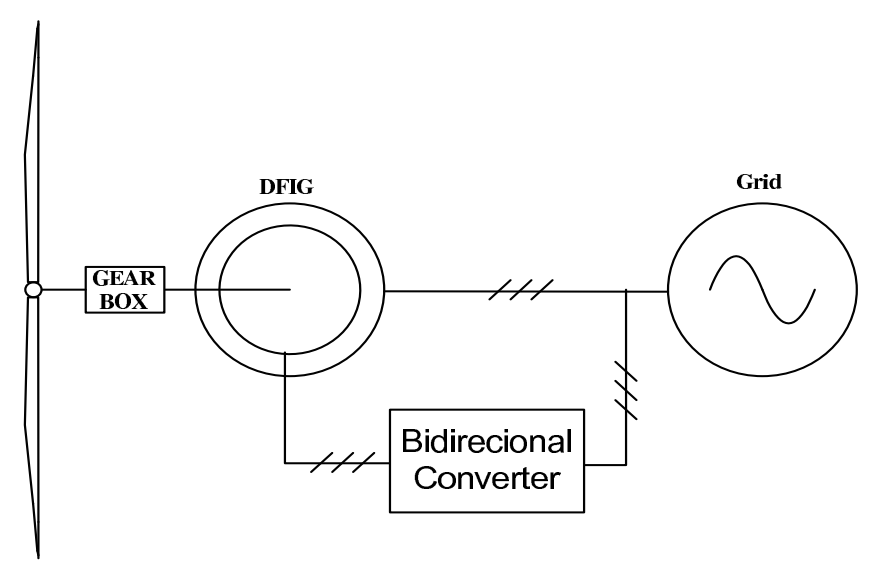

Fig. 1. Configuration of DFIG connected directly on grid.
Control of DFIG wind turbine systems is traditionally based on either stator-flux-oriented [3] or stator-voltage-oriented [4] vector control. The scheme decouples the rotor current into active and reactive power components. Control of the active and reactive power are achieved with a rotor current controller. Some investigations using PI controllers and statorflux-oriented have been presented by $[5,6]$. The problem in the use of PI controller is the tuning of the gains and the cross-coupling on DFIG terms in the whole operating range. An interesting method to solve these problems have been presented by [7-9].

Some investigations using predictive functional controller [10] and internal mode controller [11,12] have satisfactory power response when compared with the power response of PI but it is hardly to implement them due to the predictive functional controller and internal mode controller formulation.

A direct power control was proposed based on the principles of direct torque control strategy in [13-15]. This scheme calculates the required rotor controlling voltage within each sampling period directly based on the estimated stator flux, active and reactive powers and their errors. Meanwhile, a constant switching frequency was achieved by the space vector modulation (SVM) technique. However this method still encounters some problems such as over-current under grid voltage sags.

To improve the power response and to protect of rotor-side converter under grid voltage sags a proportional control with anti-jamming control has been proposed by [16]. This control has satisfactory power response and eliminate the rotor current overshoot in voltage sags when the loop of torque control is applied, although power and rotor current results was shown only in fixed speed operation. The proportional controller needs to be carefully tuned to ensure system stability and adequate response within the whole operating range and the power control with rotor current loops has a current overshoot as drawback.

This paper proposes a power control scheme for doubly-fed induction generator for variable speed wind power generation. This scheme uses stator flux decoupling and deadbeat control loops. The algorithm of the deadbeat calculates the voltage vector to be supplied to the rotor in order to guarantee that the active and reactive power reach their desired reference values. Because the generator leakage inductance and resistance information were required for this control method, the influence of the estimation errors for these parameters was also investigated. Simulations results are carried out for validation of the digital controller operation.

Manuscript received 05/12/2008; revised 30/10/2009. Accepted by recommendation of the Editor Fernando L. M. Antunes. 


\section{MACHINE MODEL AND ROTOR CURRENT VECTOR CONTROL}

Doubly-fed induction generator model in synchronous reference frame is given by [17]

$$
\begin{gathered}
\vec{v}_{1 d q}=R_{1} \vec{i}_{1 d q}+\frac{d \vec{\lambda}_{1 d q}}{d t}+j \omega_{1} \vec{\lambda}_{1 d q} \\
\vec{v}_{2 d q}=R_{2} \vec{i}_{2 d q}+\frac{d \vec{\lambda}_{2 d q}}{d t}+j\left(\omega_{1}-P P \omega_{m e c}\right) \vec{\lambda}_{2 d q}
\end{gathered}
$$

the relationship between fluxes and currents

$$
\begin{aligned}
& \vec{\lambda}_{1 d q}=L_{1} \vec{i}_{1 d q}+L_{M} \vec{i}_{2 d q} \\
& \vec{\lambda}_{2 d q}=L_{M} \vec{i}_{1 d q}+L_{2} \vec{i}_{2 d q}
\end{aligned}
$$

The machine dynamics is given by

$$
J \frac{d \omega_{m e c}}{d t}=\frac{3}{2} P P \mathcal{I} m\left(\vec{i}_{1 d q} \vec{\lambda}_{1 d q}^{*}\right)-T_{L}
$$

The generator active and reactive power are

$$
\begin{aligned}
& P=\frac{3}{2}\left(v_{1 d} i_{1 d}+v_{1 q} i_{1 q}\right) \\
& Q=\frac{3}{2}\left(v_{1 q} i_{1 d}-v_{1 d} i_{1 q}\right)
\end{aligned}
$$

The subscripts 1 and 2 represent the stator and rotor parameters respectively, $\omega_{1}$ is the synchronous speed, $\omega_{m e c}$ is the machine speed, $R_{1}$ and $R_{2}$ are the stator and rotor windings per phase electrical resistance, $L_{1}, L_{2}$ and $L_{M}$ are the proper and mutual inductances of the stator and rotor windings, $\vec{v}$ is the voltage vector, $\vec{i}$ is the current vector, $\vec{\lambda}$ is the flux vector, $P P$ is the machine number of pair of poles, $J$ is the load and rotor inertia moment and $T_{L}$ is the load torque.

The DFIG power control aims independent stator active $P$ and reactive $Q$ power control by means a rotor current regulation. For this purpose, $P$ and $Q$ are represented as functions of each individual rotor current. Using stator flux oriented control, that decouples $d q$ axis (3) becomes

$$
\begin{gathered}
i_{1 d}=\frac{\lambda_{1}}{L_{1}}-\frac{L_{M}}{L_{1}} i_{2 d} \\
i_{1 q}=-\frac{L_{M}}{L_{1}} i_{2 q}
\end{gathered}
$$

Where $\lambda_{1 d}=\lambda_{1}=\left|\vec{\lambda}_{1 d q}\right|$. The active (6) and reactive (7) power can be calculed by using (8) and (9)

$$
\begin{gathered}
P=-\frac{3}{2} v_{1} \frac{L_{M}}{L_{1}} i_{2 q} \\
Q=\frac{3}{2} v_{1}\left(\frac{\lambda_{1}}{L_{1}}-\frac{L_{M}}{L_{1}} i_{2 d}\right)
\end{gathered}
$$

Where $v_{1}=v_{1 q}=\left|\vec{v}_{1 d q}\right|$. Thus, rotor currents will reflect in stator currents and on stator active and reactive power.
Consequently this principle can be used on stator active and reactive power control of the DFIG.

\section{Rotor Side Equations}

The rotor currents control by using (10) and (11) allows the DFIG power control. The rotor voltage (2), in the synchronous referential frame using the stator flux position, and by using (8) and (9) becomes

$$
\vec{v}_{2 d q}=\left(R_{2}+j \sigma L_{2} \omega_{s l}\right) \vec{i}_{2 d q}+\sigma L_{2} \frac{d \vec{i}_{2 d q}}{d t}+j \frac{L_{m}}{L_{1}} \omega_{s l} \lambda_{1}
$$

where $\omega_{s l}=\omega_{1}-P P \omega_{m e c}$ and $\sigma=1-\frac{L_{M}^{2}}{L_{1} L_{2}}$.

In space state form (12) becomes

$$
\dot{\bar{i}}_{2}=H \bar{i}_{2}+K \bar{v}_{2}+L \bar{\lambda}_{1}
$$

$$
\begin{array}{r}
{\left[\begin{array}{c}
\frac{d i_{2 d}}{d t} \\
\frac{d i_{2 q}}{d t}
\end{array}\right]=\left[\begin{array}{cc}
\frac{-R_{2}}{\sigma L_{2}} & \omega_{s l} \\
-\omega_{s l} & \frac{-R_{2}}{\sigma L_{2}}
\end{array}\right]\left[\begin{array}{c}
i_{2 d} \\
i_{2 q}
\end{array}\right]+\left[\begin{array}{cc}
\frac{1}{\sigma L_{2}} & 0 \\
0 & \frac{1}{\sigma L_{2}}
\end{array}\right]\left[\begin{array}{l}
v_{2 d} \\
v_{2 q}
\end{array}\right]+} \\
{\left[\begin{array}{cc}
0 & \frac{\omega_{s l} L_{M}}{\sigma L_{1} L_{2}} \\
\frac{-\omega_{s l} L_{M}}{\sigma L_{1} L_{2}} & 0
\end{array}\right]\left[\begin{array}{c}
\lambda_{1} \\
0
\end{array}\right]}
\end{array}
$$

Due to the fact that the mechanical time constant is much greater then the electrical time constants. Thus $\omega_{m e c}=$ constant is a valid approximation for each sample period [1820]. Hence the slip speed $\omega_{s l}=$ constant, due to the synchronous speed $\omega_{1}=2 \pi f$ was fixed by the grid and $f=60 \mathrm{~Hz}$

\section{THE STATOR FLUX DECOUPLING AND DEADBEAT CONTROL}

The algorithms of the stator flux decoupling and deadbeat calculate the input $\bar{u}(k)$ in order to guarantee that the output $\bar{x}(k)$ reach their desired reference values using a discrete equation of the continuous linear system [21,22].

A linear continuous system is represented by

$$
\begin{array}{r}
\dot{\bar{x}}=A \bar{x}+B \bar{u}+G \bar{w} \\
\bar{y}=C \bar{x}
\end{array}
$$

where $\bar{w}$ denotes the perturbation vector and $A, C, B$ and $G$ $n \times n$ matrices. In this paper $C=I$, where $I$ is the identity matrix.

Equation (15) can be discretized considering $T$ as the sampling period and $k$ as the sampling time by using zeroorder-hold $(\mathrm{ZOH})$ with no delay as

$$
\bar{x}(k+1)=A_{d} \bar{x}(k)+B_{d} \bar{u}(k)+G_{d} \bar{w}(k)
$$

where

$$
\begin{array}{r} 
\\
A_{d}=e^{A T} \cong I+A T \\
B_{d}=\int_{0}^{\tau} e^{A T} B d \tau \cong B T \\
G_{d}=\int_{0}^{\tau} e^{A T} G d \tau \cong G T
\end{array}
$$

The input $\bar{u}$ equation at the $(k-1)$ th sampling instant is given by

$$
\bar{x}(k)=A_{d} \bar{x}(k-1)+B_{d} \bar{u}(k-1)+G_{d} \bar{w}(k-1)
$$


Because $G_{d} \bar{w}(k)$ and $G_{d} \bar{w}(k-1)$ is approximately equal, hence, combining (16) and (18) yields an expression which contains only the inputs $\bar{u}$ and outputs $\bar{x}$.

$$
\begin{array}{r}
\bar{u}(k)=\bar{u}(k-1)+ \\
B_{d}^{-1}\left[(\bar{x}(k+1)-\bar{x}(k))-A_{d}(\bar{x}(k)-\bar{x}(k-1))\right]
\end{array}
$$

Equation (19) indicates that the input can be calculated by using the outputs at the $k-1, k$ and $k+1$ th sampling instant. This relationship can be used to calculate the input need to procedure the reference at each control instant because both the feedback and the reference at $k-1$ and $\mathrm{k}$ sampling period instant are available when (19) is evaluated, either of them can be used in creation of the input.

The control law that uses the reference $\bar{x}_{r e f}$ at the $k+1$ and $k$ th sampling instants to calculate the input $\bar{u}_{f f}$ can be formulated as

$$
\begin{array}{r}
\bar{u}_{f f}(k)=\bar{u}(k-1)+ \\
B_{d}^{-1}\left[\left(\bar{x}_{r e f}(k+1)-\bar{x}(k)\right)-A_{d}\left(\bar{x}_{r e f}(k)-\bar{x}(k-1)\right)\right]
\end{array}
$$

where $\bar{x}_{r e f}(k+1)$ and $\bar{x}_{r e f}(k)$ is the reference at $k+1$ and $k$ sampling instant. The total input applied is given by

$$
\bar{u}_{r e f}(k)=\bar{u}_{f f}(k)+\bar{u}_{f b}(k)
$$

where $\bar{u}_{f b}$ is achieved making (19) - (20), considering that $A_{d}$ and $B_{d}$ was estimated correctly and treating the modeling errors as a disturbance to the controlled output, then it can be simplified by replacing the output with output errors that is given by

$$
\Delta \bar{x}(k+1)=A_{d} \Delta \bar{x}(k)+B_{d} \bar{u}_{f b}(k)
$$

where $\Delta \bar{x}(k)=\bar{x}_{\text {ref }}(k)-\bar{x}(k)$. Note that when realizing the control, $\bar{x}_{r e f}(k+1)$ is not available at the time when $\bar{u}_{f f}$ is calculated. Therefore, $\bar{x}_{r e f}(k)$ must be used instead $\bar{x}_{r e f}(k+1)$. In essence, the control reference must be delayed one sampling period in the control. The effect of delaying the reference one sampling period will shift the output response back one sampling period as well, but the shape of the output response remains the same.

To achieve a fast output response and a null steady state error a separate deadbeat control is made by using (22) and making $\bar{u}_{f b}(k)=-G_{c} \Delta \bar{x}(k)$. One is given by

$$
\Delta \bar{x}(k+1)=\left(A_{d}-B_{d} G_{c}\right) \Delta \bar{x}(k)
$$

From (23) the gains required to null steady state error are found by $\left(A_{d}-B_{d} G_{c}\right)=0$.

The block diagram representing (20) and (23) is shown in Figure 2

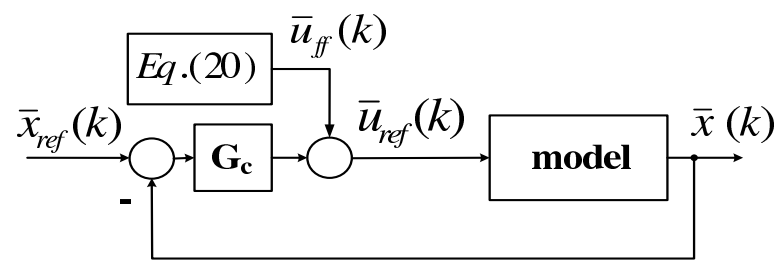

Fig. 2. Stator flux decoupling and deadbeat control block diagram.

\section{A. Power Control}

The control scheme uses a stator flux decoupling and deadbeat control to obtain rotor voltages that should be applied on generator in order to guarantee active and reactive power reach their desired reference values. The digital power control block diagram is shown in Figure 3. The converter that is connected to the grid control the voltage of the link DC and one can be controlled by using any control presented in [23].

Since the applied rotor voltage is also constant during a power control period for voltage-fed PWM then (14) can be discretized at $k$ th sampling instant and expressed in the state space form using (16) and making $\bar{x}=\bar{i}_{2}, A=H, B=$ $K, \bar{u}=\bar{v}_{2}, G=L$ and $\bar{w}=\bar{\lambda}_{1}$. It is given by equation

$$
\begin{aligned}
{\left[\begin{array}{c}
i_{2 d}(k+1) \\
i_{2 q}(k+1)
\end{array}\right]=} & {\left[\begin{array}{cc}
1-\frac{R_{2} T}{\sigma L_{2}} & \omega_{s l} T \\
-\omega_{s l} T & 1-\frac{R_{2} T}{\sigma L_{2}}
\end{array}\right]\left[\begin{array}{l}
i_{2 d}(k) \\
i_{2 q}(k)
\end{array}\right]+} \\
& +\left[\begin{array}{cc}
\frac{T}{\sigma L_{2}} & 0 \\
0 & \frac{T}{\sigma L_{2}}
\end{array}\right]\left[\begin{array}{l}
v_{2 d}(k) \\
v_{2 q}(k)
\end{array}\right]+ \\
& +\left[\begin{array}{cc}
0 & \frac{\omega_{s l} L_{M} T}{\sigma L_{1} L_{2}} \\
\frac{-\omega_{s l} L_{M} T}{\sigma L_{1} L_{2}} & 0
\end{array}\right]\left[\begin{array}{c}
\lambda_{1}(k) \\
0
\end{array}\right]
\end{aligned}
$$

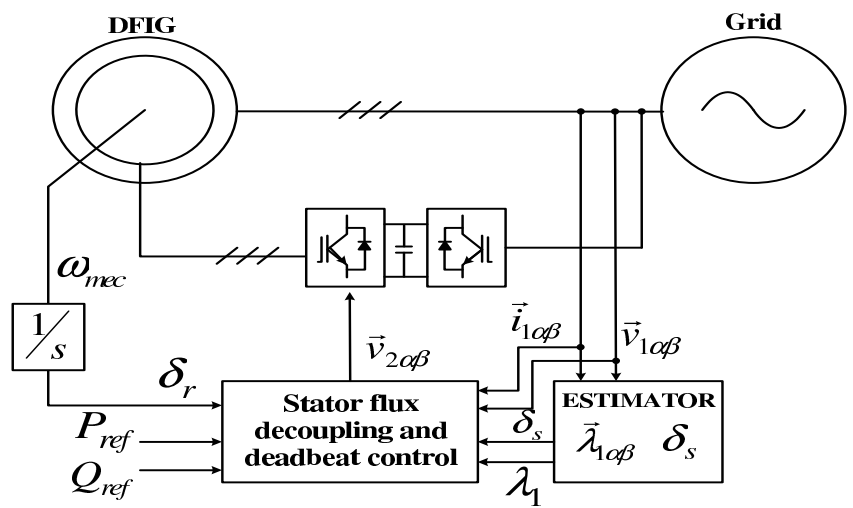

Fig. 3. Power control block diagram.

The rotor voltage can be calculated by using the rotor currents at the $k-1, k$ and $k+1$ th sampling instant that can be seen in (20) and (24) and it is given by

$$
\begin{array}{r}
\vec{v}_{2 d q_{f f}}(k)=\vec{v}_{2 d q}(k-1)+ \\
+\frac{\sigma L_{2}}{T}\left[\left(\vec{i}_{2 d q_{r e f}}(k+1)-\vec{i}_{2 d q}(k)\right)\right]+ \\
-\left(\frac{\sigma L_{2}}{T}-R_{2}\right)\left[\left(\vec{i}_{2 d q_{r e f}}(k)-\vec{i}_{2 d q}(k-1)\right)\right]+ \\
-j \sigma L_{2} \omega_{s l}\left[\left(\vec{i}_{2 d q_{r e f}}(k)-\vec{i}_{2 d q}(k-1)\right)\right]
\end{array}
$$

To eliminate the steady-state errors of active and reactive power caused by the system parameter mismatch that is replaced to current as errors and to improve the accuracy of the proposed power control methods in accordance to (23) the gain required is

$$
G_{c}=\frac{\sigma L_{2}}{T}\left(1-\frac{R_{2} T}{\sigma L_{2}}-j \omega_{s l} T\right)
$$


For the active power control, the rotor current reference by using (10) is given by

$$
i_{2 q_{r e f}}(k+1)=i_{2 q_{r e f}}(k)=-\frac{2 P_{r e f} L_{1}}{3 v_{1} L_{M}}
$$

and for the reactive power control by using (11) the rotor current reference is

$$
i_{2 d_{r e f}}(k+1)=i_{2 d_{r e f}}(k)=-\frac{2 Q_{r e f} L_{1}}{3 v_{1} L_{M}}+\frac{\lambda_{1}}{L_{M}}
$$

Thus, if the $\mathrm{d}$ and $\mathrm{q}$ axis voltage components are calculated according (25), (26), (27) and (28) above are applied to the generator, then the active and reactive power convergence to their respective commanded values will occur. The desired rotor voltage in the rotor $\alpha \beta$ reference frame generates switching signals for the rotor side using either space vector modulation that is given by $v_{2 \alpha \beta}=v_{2 d q} e^{\delta_{s}-\delta_{r}}$.

Stator currents and voltages, rotor speed and currents are measured to stator flux position $\delta_{s}$ and magnitude $\lambda_{1}$, synchronous frequency $\omega_{1}$ and slip frequency $\omega_{s l}$ estimation.

\section{B. Estimation}

To digital power control is required to calculate the active and reactive power values, their errors, the stator flux magnitude and position, the slip speed and synchronous frequency.

The flux estimation using (1) is given by

$$
\vec{\lambda}_{1 \alpha \beta}=\int\left(\vec{v}_{1 \alpha \beta}-R_{1} \vec{i}_{1 \alpha \beta}\right) d t
$$

and the flux position by using (29) as

$$
\delta_{s}=\arctan \left(\frac{\lambda_{1 \beta}}{\lambda_{1 \alpha}}\right)
$$

The synchronous speed $\omega_{1}$ estimation is given by

$$
\omega_{1}=\frac{d \delta_{s}}{d t}=\frac{\left(v_{1 \beta}-R_{1} i_{1 \beta}\right) \lambda_{1 \alpha}-\left(v_{1 \alpha}-R_{1} i_{1 \alpha}\right) \lambda_{1 \beta}}{\left(\lambda_{1 \alpha}\right)^{2}+\left(\lambda_{1 \beta}\right)^{2}}
$$

and the slip speed estimation by using the rotor speed and synchronous speed is

$$
\omega_{s l}=\omega_{1}-P P \omega_{m e c}
$$

The rotor reference frame angle is given by

$$
\delta_{s}-\delta_{r}=\int \omega_{s l} d t
$$

\section{IMPACT OF PARAMETERS VARIATONS ON SYSTEM PERFORMANCE}

The analysis of impact of parameters variations was made by using (25), (26), (27) and (28), that allows rotor voltage calculation. The stator resistance used in stator flux estimation and the rotor resistance used in rotor voltage calculation have negligible impact on system performance for high power generators $[4,15]$. The accuracy of the rotor voltage calculation is influenced by the constant $\sigma L_{2}$ and the inductance ratio $L_{1} / L_{M}$ that are determined by the stator and rotor leakage and magnetization inductance. Since the leakage flux magnetic path is mainly air, the variation of the leakage inductance during operation is insignificant [15]. However, magnetization inductance variation needs to be considered due to possible variation of the magnetic permeability of the stator and rotor cores under different operating conditions. The required parameters can be simplified considering the relatively small leakage inductance $L_{l 1}$ and $L_{l 2}$ compared to the magnetization inductance $L_{M}$ that is shown in Appendix and it is given by

$$
\sigma L_{2} \cong\left(L_{l 1}+L_{l 2}\right), \frac{L_{1}}{L_{M}}=\frac{L_{M}+L_{l 1}}{L_{M}} \cong 1
$$

Equation (34) shows that the variations of $L_{M}$ has little impact in $\sigma L_{2}$ and $L_{1} / L_{M}$ and therefore, its influence on the performance of the proposed control strategy would also be insignificant.

\section{SIMULATION RESULTS}

In the simulation of proposed digital control strategy was used MATLAB/SimPowerSystemspackage. The digital power control strategy has a $T=10^{-4} s$ and the DFIG parameters are shown in Appendix. Figure 3 shows the schematic of the implemented system, the inverter was modeled as controlled voltage sources and the energy stored by the DC link capacitor was dissipated on a resistor load by using a hysteresis control of one IGBT in series with a diode.

To the power factor (PF) control the reactive power reference is given by

$$
Q_{r e f}=P_{r e f} \frac{\sqrt{1-P F^{2}}}{P F}
$$

Initial studies with various active and reactive power steps and constant rotor speed at $226.6 \mathrm{rad} / \mathrm{s}$ were carried out to test the dynamic response of the proposed power control strategy and it is shown at Figure 4(a). The initial active power and power factor references were being $-60 \mathrm{~kW}$ and $\mathrm{FP}=+0.85$.

The active power and power factor references were step changed from -60 to $-100 \mathrm{~kW}$ and from PF of 0.85 to -0.85 at $2.5 \mathrm{~s}$ and the power reference were step changed again from -100 to $-149.2 \mathrm{~kW}$ and from PF of -0.85 to 1 at $2.75 \mathrm{~s}$, respectively. The rotor currents in synchronous referential is shown in Figure 4(b) and rotor speed, the rotor and stator currents in the stationary referential are shown in Figure 5. The dynamic response of both active and reactive powers are in few milliseconds, there is no overshoot of either stator/rotor or the active/reactive powers and the satisfactory performance and robustness of the controller can be seen. 


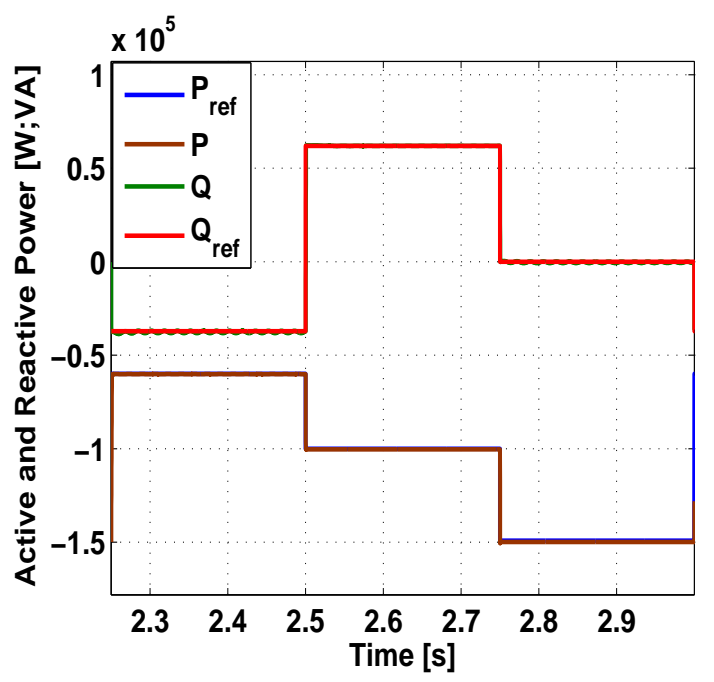

(a) Response of step of active and reactive power.

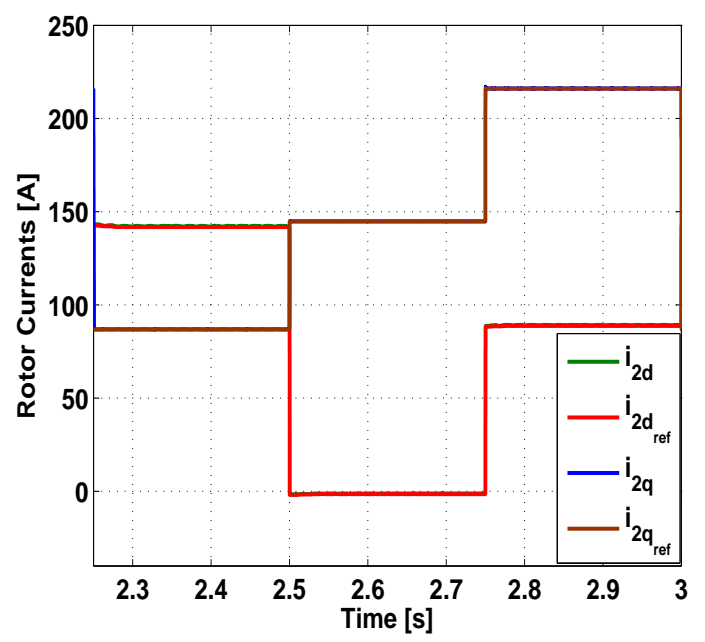

(b) Response of step of rotor currents in synchronous referential.

Fig. 4. Response of step tests for active and reactive power and rotor currents in supersynchronous operation.

Studies with various power steps and rotor speed were carried out to further test the proposed power control strategy. During the period 2.5-2.84 s, the rotor speed increased from $151.1 \mathrm{rad} / \mathrm{s}$ to $226.6 \mathrm{rad} / \mathrm{s}$. The Figure 6(a) shows the results step reference tests of active and reactive power. The power steps, i.e., active power and power factor references were changed from -60 to $-100 \mathrm{~kW}$ and from PF of 0.85 to -0.85 at $2.5 \mathrm{~s}$. The rotor currents in synchronous referential is shown in Figure 6(b) and the rotor speed, the rotor and stator currents in the stationary referential are shown in Figure 7 and the controlled capacitor voltage is presented in Figure 8 . The oscillations occurs due to the fact the voltage was controlled by an hysteresis controller and the controller gives a signal to open or close the IGBT in accordance with the error between the voltage reference and the DC link voltage. The satisfactory performance and robustness of the controller can be seen due to the fact that the active and reactive power reach their desired reference values when the rotor speed varies.

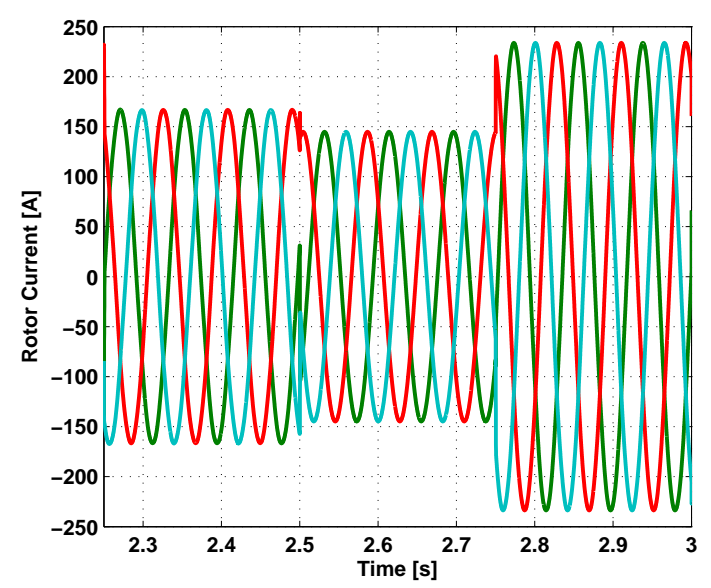

(a) Rotor currents.

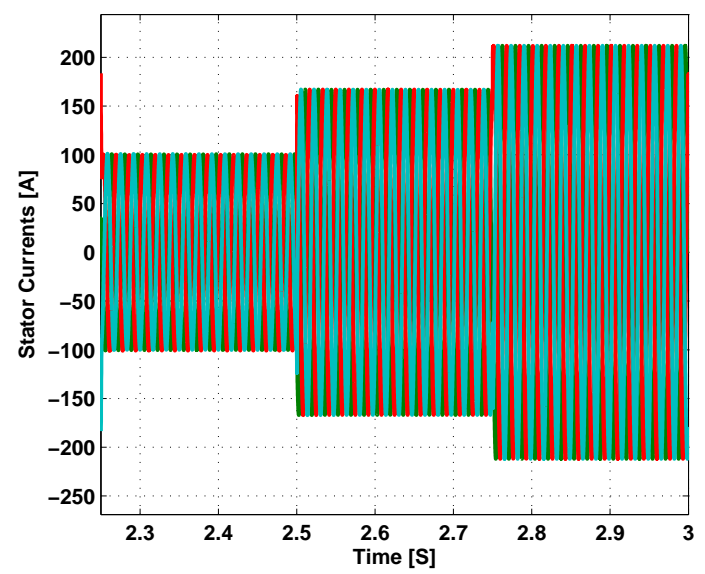

(b) Stator currents.

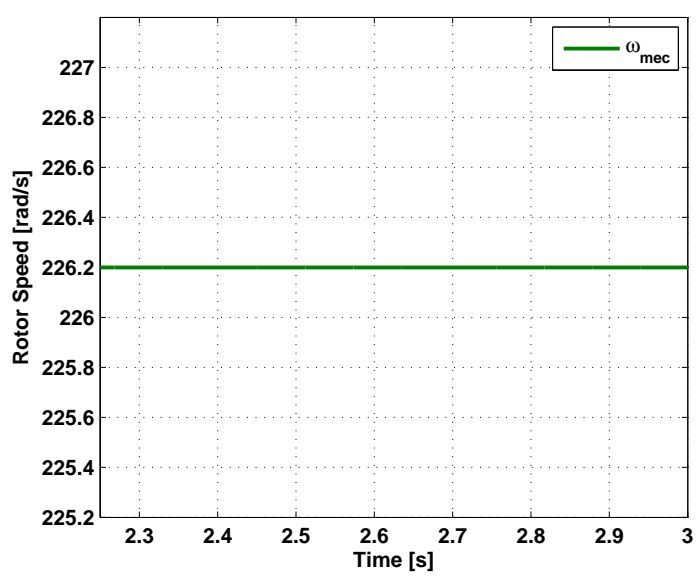

(c) Rotor Speed.

Fig. 5. Stator and rotor currents and rotor speed.

To test the impact of the parameters variations on the system performance the rotor resistance $R_{2}$ and magnetization inductance $L_{M}$ of DFIG are increased of $20 \%$. The same tests of step reference of active and reactive powers with rotor speed variation and with parameters variation are shown in Figures 9 and 10. Comparing Figures 6 and 9 and Figures 7 
and 10 , there is hardly any difference, and even with such large inductance and rotor resistance errors, the system maintains satisfactory performance under both steady-state and transient conditions. This occurs due to it was considered that the parameters were estimated correctly and the modeling errors were considered a disturbance to the controlled output in the controller formulation in wich it was presented in (23).

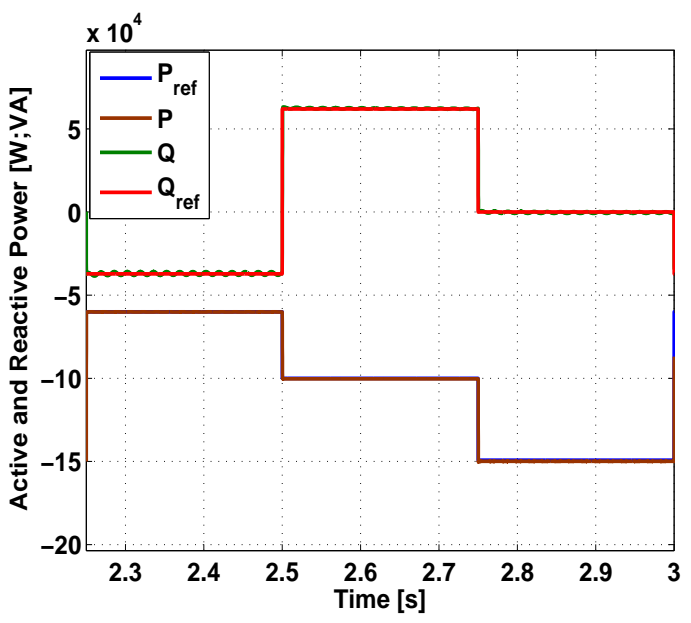

(a) Response of step of active and reactive power.

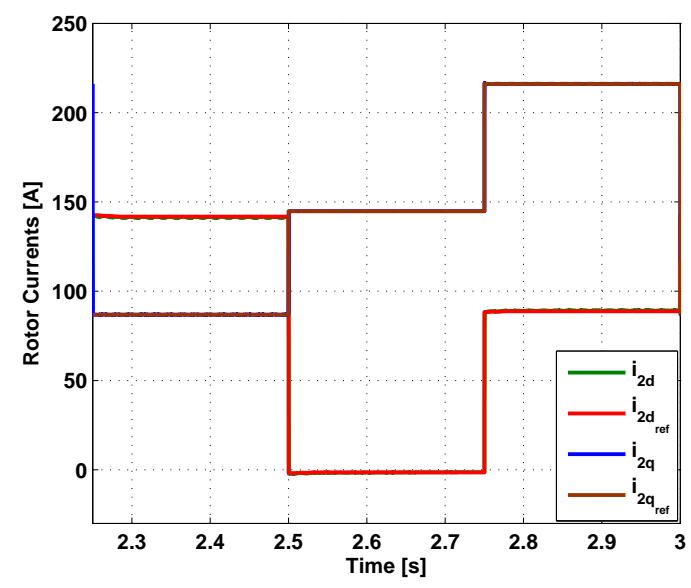

(b) Response of step of rotor currents in synchronous referential.

Fig. 6. Response of step tests for active and reactive power and rotor currents with several speed operation.

\section{CONCLUSION}

This paper has presented a power control scheme for doubly-fed induction generator using stator flux decoupling and deadbeat control loops. The controllers use the DFIG equations to calculate the required rotor voltages in order to the active and the reactive power values reach the desired reference values. This strategy has a similar power response of the direc power control presented in $[14,15]$ and the constant switching frequency overcomes the drawbacks of conventional DPC $[13,14]$.

The impact of machine parameters variations was also analyzed and found to be negligible due to it was considered that the parameters were estimated correctly and the modeling errors were considered a disturbance to the controlled output in the controller formulation. The simulations confirm the effectiveness and the robustness of the power controller during several operating conditions and variations of machine parameters.

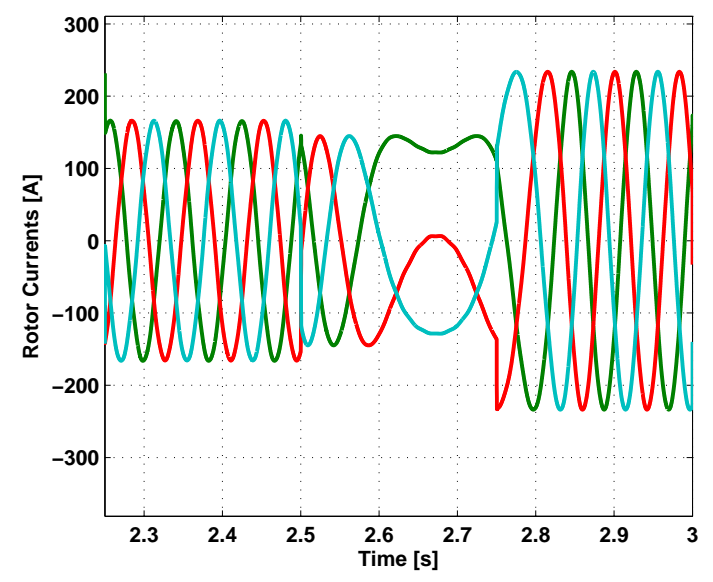

(a) Rotor currents.

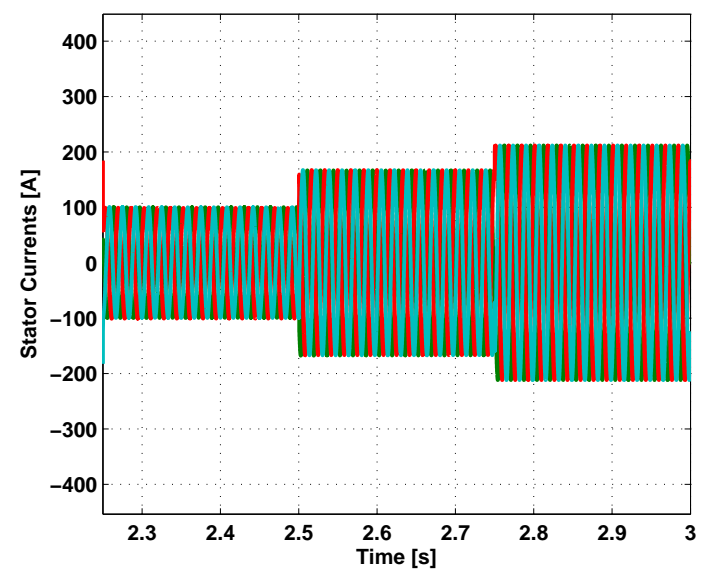

(b) Stator currents.

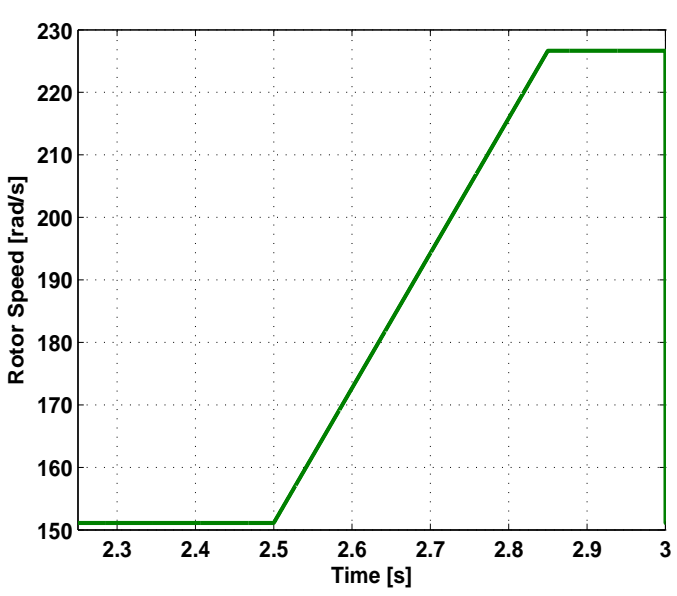

(c) Rotor Speed.

Fig. 7. Stator and rotor currents and rotor speed. 


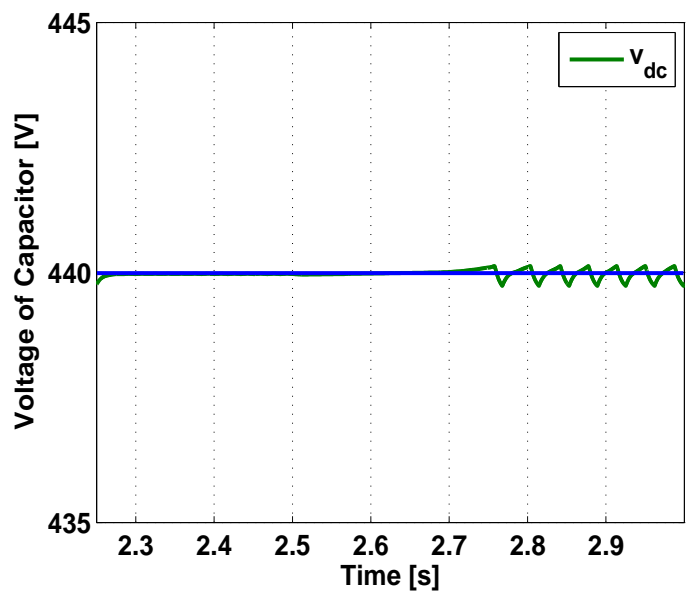

Fig. 8. DC link voltage.

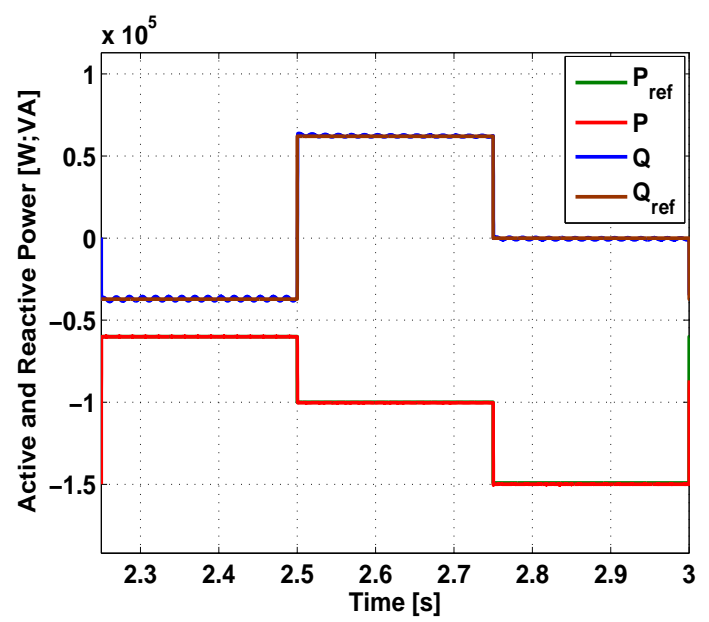

(a) Response of step of active and reactive power.

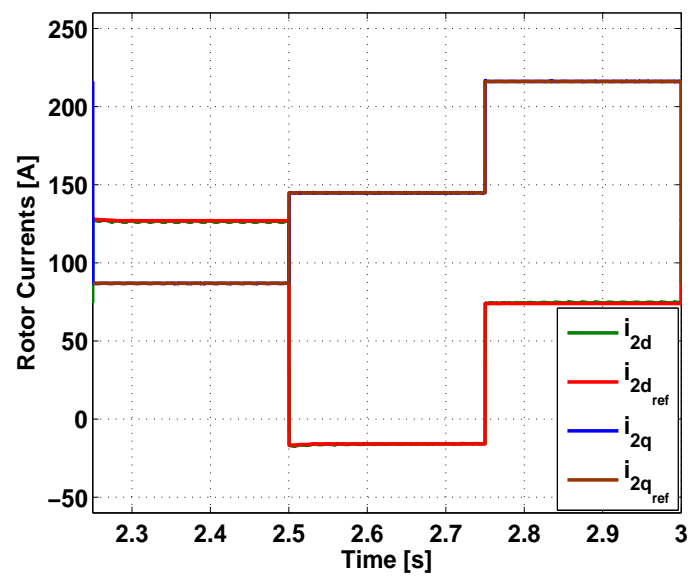

(b) Response of step of rotor currents in synchronous referential.

Fig. 9. Response of step tests for active and reactive power and rotor currents with several speed operation.

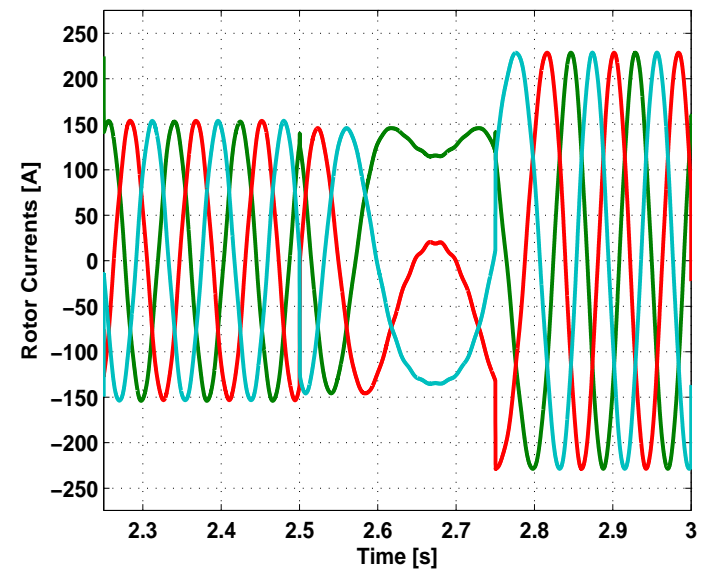

(a) Rotor currents.

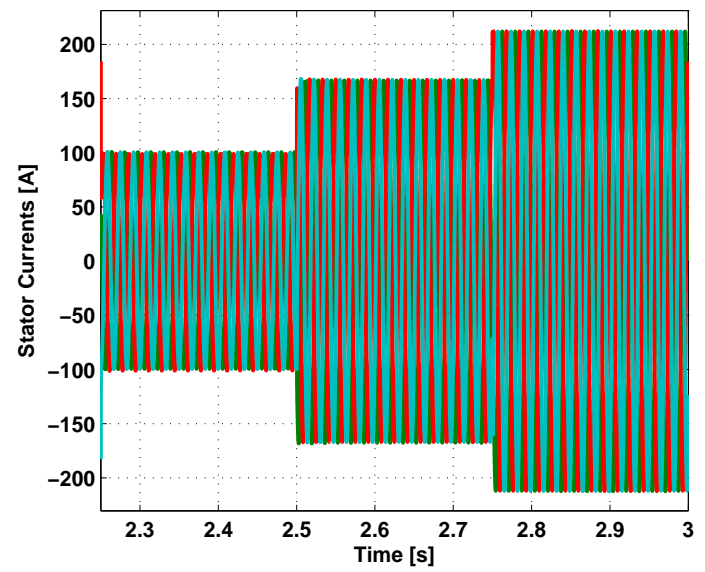

(b) Stator currents.

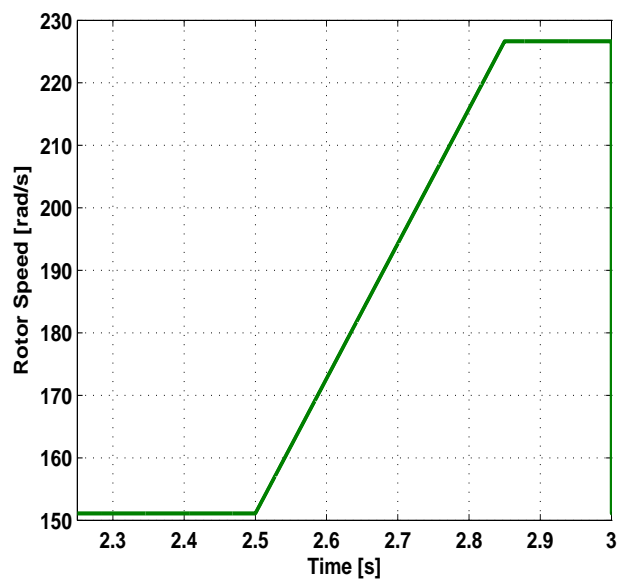

(c) Rotor Speed.

Fig. 10. Stator and rotor currents and rotor speed.

\section{REFERENCES}

[1] M. Godoy Simões and F. A. Farret. Renewable Energy Systems with Induction Generators. CRC PRESS, 2004.

[2] R. Datta and V. T. Rangathan. Variable-speed wind power generation using doubly fed wound rotor induction 
machine - a comparison with alternative schemes. IEEE Trans. on Energy Conversion, 17(3):414-421, September 2002.

[3] B. H. Chowdhury and S. Chellapilla. Double-fed induction generation control for variable speed wind power generation. Electric Power System Research, (76):786-800, 2006.

[4] B. Hopfensperger, D. J. Atkinson, and R.A. Lakin. Stator-f lux-oriented control of a doubly-fed induction machine with and without position encoder. IEE Proc.Electr. Power Applications, 147(4):241-250, April 2000.

[5] A. Tapia, G. Tapia, J. X. Ostolaza, and J. R. Sáenz. Modeling and control of a wind turbine driven doubly fed induction generator. IEEE Trans. on Energy Conversion, (194-204), June 2003.

[6] E. Bim and R. V. Jacomini. Controle do fator de potência de um gerador de indução duplamente alimentado conectado á rede-operação com escorregamento positivo. CBA/2008 - Congresso Brasileiro de Automática, 2008.

[7] J. P. da Costa, J. Marques, H. A. Gründling, and H. Pinheiro. Dynamic behavior of the doubly-fed induction generator in stator flux vector reference frame. Eletrônica de Potência, 13(1):33-42, March 2006.

[8] R. G. de Oliveira, J. L. da Silva, and S. R. Silva. Development of a new reactive power control strategy in doubly-fed induction generators for wind turbines. Eletrônica de Potência, 13(4):277-284, November 2008.

[9] F. Poitiers. anb T. Bouaouiche and M. Machmoum. Advanced control of a doubly-fed induction generator for wind energy conversion. Electric Power Systems Research, 79:1085-1096, 2009.

[10] Z. Xin-fang, X. Da-ping, and L. Yi-bing. Predictive functional control of a doubly fed induction generator for variable speed wind turbines. IEEE World Congress on Intelligent Control and Automation, June 2004.

[11] J. Morren and Sjoerd W. H. de Haan. Ridethrough of wind turbines with doubly-fed induction generator during a voltage dip. IEEE Transactions on Energy Conversion, 20(2):435-441, June 2005.

[12] J. Guo, X. Cai, and Y. Gong. Decoupled control of active and reactive power for a grid-connected doublyfed induction generator. Third International Conference on Electric Utility Deregulation and Restructuring and Power Technologies. DRPT 2008., pages 2620 - 2625, April 2008.

[13] R. Datta and V. T. Ranganathan. Direct power control of grid-connected wound rotor induction machine without rotor position sensors. IEEE Transactions on Power Electronics, 16(3):390 - 399, May 2001.

[14] L. Xu and P. Cartwright. Direct active and reactive power control of dfig for wind energy generation. IEEE Trans. on Energy Conversion, 21(3):750-758, September 2006.

[15] D. Zhi and L. Xu. Direct power control of dfig with constant switching frequency and improved transient performance. IEEE Trans. on Energy Conversion, 22(1):110-118, March 2007.

[16] G. Xiao-Ming, S. Dan, H. Ben-Teng, and H. Ling-Ling. Direct power control for wind-turbine driven doubly- fed induction generator with constant switch frequency. International Conference on Electrical Machines and Systems, pages 253-258, October 2007.

[17] W. Leonhard. Control of Electrical Drives. SpringerVerlag Berlin Heidelberg New York Tokyo, 1985.

[18] S. Yamamura. Spiral Vector Theory of AC Circuits and Machines. Clarendon Press OXFORD, 1992.

[19] J. Holtz, J. Quan, J. Pontt, J. Rodríguez, P. Newman, and $\mathrm{H}$. Miranda. Design of fast and robust current regulators for high-power drives based on complex state variables. IEEE Trans. Ind. Applications, 40:1388-1397, September/October 2004.

[20] A. J. Sguarezi Filho and E. Ruppert Filho. The complex controller for three-phase induction motor direct torque control. Sba Controle e automação., 20(2):256-262, 2009.

[21] G. F. Franklin, J. D. Powel, and M. L. Workman. Digital Control of Dynamic Systems. Addison-Wesley Publishing Company, 1994.

[22] S.-M. Yang and C.-H. Lee. A deadbeat current controller for field oriented induction motor drives. IEEE Trans. on Power Electronics, 17(5):772-778, 2002.

[23] J. R. Rodríguez, J. W. Dixon, J. R. Espinoza, J. Pontt, and P. Lezana. Pwm regenerative rectifiers: State of the art. IEEE Trans. Ind. Electronics, 52(1), February 2005.

\section{APPENDIX}

\section{A. Effect of parameters in the Rotor Voltage Calculation}

Considering that $L_{l 1}<<L_{M}$ and $L_{l 2}<<L_{M}$, the $\sigma L_{2}$ and $\frac{L_{1}}{L_{M}}$ can be simplified as

$$
\begin{array}{r}
\sigma L_{2}=L_{2}-\frac{L_{M}^{2}}{L_{1}}=\frac{L_{1} L_{2}-L_{M}^{2}}{L_{1}}= \\
=\frac{\left(L_{l 1} L_{l 2}\right)+L_{M}\left(L_{l 1}+L_{l 2}\right)+L_{M}^{2}-L_{M}^{2}}{L_{l 1}+L_{M}} \cong \\
\cong \frac{L_{M}\left(L_{l 1}+L_{l 2}\right)}{L_{M}}=\left(L_{l 1}+L_{l 2}\right)
\end{array}
$$

and

$$
\frac{L_{1}}{L_{M}}=\frac{L_{M}+L_{l 1}}{L_{M}}=1+\frac{L_{l 1}}{L_{M}}
$$

\section{B. Doubly-fed induction generator parameters}

$R_{1}=0.02475 \Omega ; R_{2}=0.0133 \Omega ; L_{m}=0.01425 \mathrm{H} ;$ $L_{l 1}=0.000284 \mathrm{H} ; L_{l 2}=0.000284 \mathrm{H} \mathrm{H} ; J=2.6 \mathrm{Kg} \cdot \mathrm{m}^{2}$; $P P=2 ; P N=149.2 \mathrm{kVA} ; V_{N}=575 \mathrm{~V}$.

\section{BIOGRAPHIES}

Alfeu J. Sguarezi Filho received his bachelor degree on Electrical Engineering from Faculdade Área 1 and his Master degrees from Campinas University in Brazil, respectively in 2005 and 2007. He is working now toward the $\mathrm{PhD}$ degree at Campinas University. His research interests are electrical machines drive, electrical power systems, power control and doubly-fed induction generator for disperse generation use. Mr. Sguarezi is SOBRAEP member since June 2007. 
Milton E. de Oliveira Filho was born in Bom Jesus da Lapa, Bahia, 1966. He graduated as electrical engineer from Universidade Federal de Itajubá, Itajubá (1995) and as MSc in same university (1998). He is currently designer engineer at General Electric Hydro Inepar, Campinas and working on his $\mathrm{PhD}$ thesis at Campinas University, Brazil. His research interests are matrix converters, active power filters, and large power drives. Mr Milton is a member of SOBRAEP since June 2007.

Ernesto Ruppert Filho received his bachelor degree in Electrical Engineering and his Master and $\mathrm{PhD}$ degrees from Campinas University in Brazil, respectively in 1971, 1974 and 1983. From 1972 to 1978 he had been working at Electrical and Computer Enginneering School of Campinas University as an Assistance Professor in the Electromechanical Energy Conversion area, from 1979 to 1983 he had been working for General Electric in Brazil designing large induction and synchronous motors and working as an Application Engineer dedicated to large motors and generators, from 1983 to 1989 he had been working for Vigesa Heavy Equipments in Brazil designig very large hydrogenerators and also performing commissionig testes in some hydro power plants in Brazil. From 1989 to 1992 he runned his own company dealing with electrical installations and from 1992 up to now he is working as Full Professor at the Electrical and Computer Engineering School of Campinas University, in Campinas, Brazil, researching and teaching in the areas of Electrical Machines, Power Electronics, Drives and Electrical Power Systems. 